\title{
Innovative approaches to training professionals working with young children with disabilities
}

\author{
Yu.Ye. Vyatleva ${ }^{1 *}$, N.Yu. Grigorenko ${ }^{2}$, and Yu.A. Pokrovskaya ${ }^{3}$ \\ ${ }^{1}$ Laboratory of special training and education, «Logomag» LLC, Moscow, Russia \\ ${ }^{2}$ Moscow City University, Moscow, Russia \\ ${ }^{3}$ Moscow City University, Moscow, Russia
}

\begin{abstract}
The article is devoted to the topical issues of vocational training of experts working with young children with disabilities. The necessity of discussion of the issue is based on the expansion of the age limits of correction influence and the creation of a system of early intervention for families raising children with disorders. According to that, the issue of training highly qualified professionals has become vital both for the system of special education and for those who need professional assistance.
\end{abstract}

\section{A problem statement}

One of the most important directions in the practice of pedagogical correction work with disabled children is early speech therapy assistance. Started at the initial stages of development (first years of life) it increases the effectiveness of the development of communicative abilities that actively support timely and successful socialization of these children $[1,2]$.

It is therefore very important that a speech therapist working with these children should possess the following professional knowledge, abilities and skills, such as basic picture of the ontogenesis and dysontogenesis of the psycho-speech activity of the child; technologies of timely detection of problematic development in young children; ability to use different methods of overcoming the limitations of psycho-speech development and stimulation of communication speech activity; successful experience in applying various practices of productive communication speech interaction between the child and its parents and inner circle including peers; good skills of using game, visual, technical, information and multimedia tools for personalized acquiring essential skills; ability to apply network resources for replenishment of the personal professional library and sharing experience with professional community $[3,4,5,6]$.

\subsection{The objective of the work}

In this context, modern developments in the field of monitoring of different trajectories of development, especially the development of communicative functions among young

*Corresponding author: ipcs-profped@yandex.ru 
children, are becoming relevant, being basic elements of their successful socialization [7, $8]$.

The research by Grigorenko N.Y. developed assessment and classification of young children with different types of dysontogenesis by levels. To optimize diagnostic work, the author highlighted parameters of the examination and analysis criteria and developed precise step-by-step guidance and adapted methodical recommendations for the full interaction between the child's parents and the experts [9: 128-183; 206-250].

In the classification, Grigorenko N.Y. identified four levels of communicative development among young children. Each level is described in accordance with the highlighted parameters and allows the assessing the state of communicational development in the dynamics of its progression from complete absence of the need of communication between a child and its close environment to notable need of communication and its active manifestation. The author assesses not only the current state of communicative functions, but also thoroughly analyzes the general psycho-speech development of children depending on nosology in their anamnesis. The algorithms of correctional work for each level of communicative development developed by Grigorenko N.Y. are important metholodical support for experts and parents of babies, according to which personal strategies of special education and parenting are further built for each particular child considering its individual way of development [9: 186-193].

\section{Materials and the results of the research}

Testing this technology during long period of time (2007-2020) basing on structural unit of educational organizations of Moscow and Moscow region showed high validity of the methodology and representativeness of the data that were obtained on the basis of psychopedagogical examination and monitoring of the psycho-speech and communicative development of 586 young children (Fig. 1).

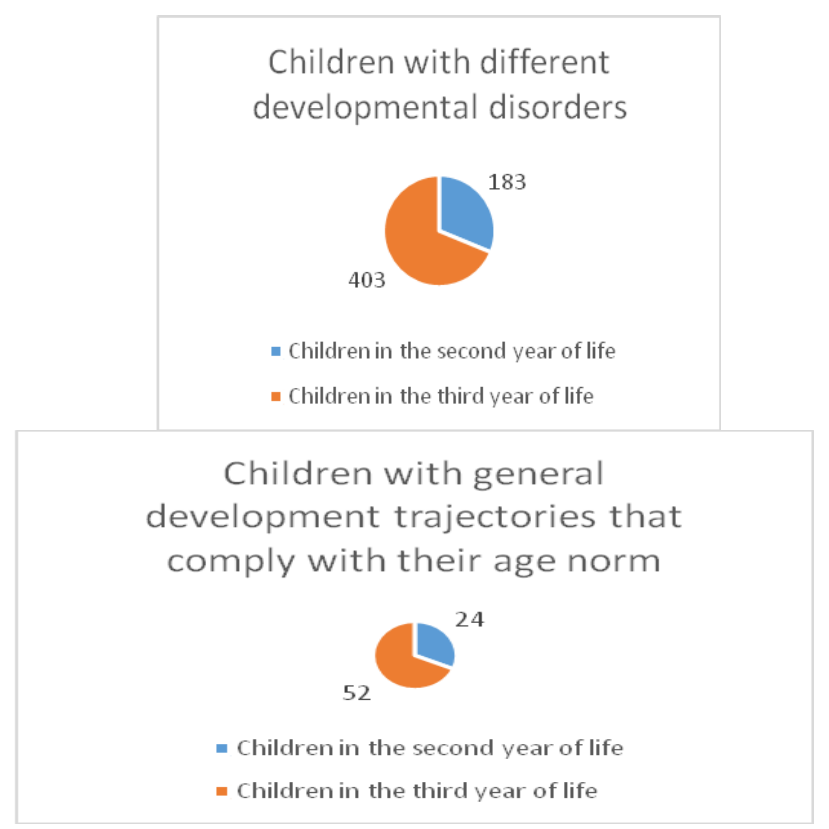

Fig. 1. Validity of the methodology and representativeness of data obtained on the basis of psychological and pedagogical survey. 
According to the results of the psycho-pedagogical examination of the test subjects, four experimental groups were conditionally identified and described corresponding to the four levels of communicative development, according to the classification by Grigorenko N.Y: EG1 corresponding to the first level of communicative development (hereinafter abbreviated CD) including 12\% of test subjects, EG2 (second level of CD) including 18\% of all children, EG3 (third level of CD) including 26\% of children and EG4 (fourth level of CD) including 44\% of children [9: 183-193; 10: 81-90] (Fig. 2).

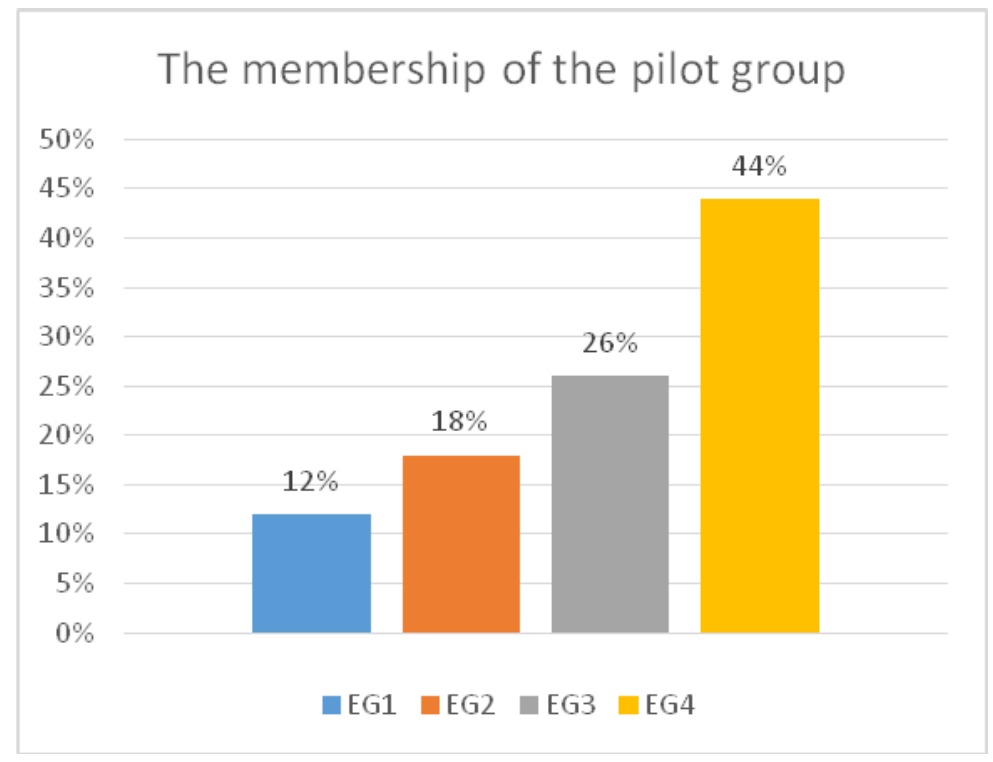

Fig. 2. Four experimental groups were conditionally identified and described corresponding to the four levels of communicative development (\%).

For the implementation of the control experiment the four groups were divided into two subgroups, one of which was taught by experiential learning due to the recommended algorithms, while the other was educated under the traditional methodology without using the methodological recommendations by Grigorenko N.Y. Thanks to the long-term analysis, generalization and interpretation of the results, the final data that were received in the experiment testify in favor of the discussed technology by Grigorenko N.Y. In EG1 $74 \%$ of the test subjects had improvement in all parameters of the survey, in particular communicative development, in EG2 it was $85 \%$, in EG3 it was $88 \%$ and in EG4 it was $92 \%$, whilst in CG1, CG2, CG3 and CG4 it was $52 \%, 64 \%, 70 \%$ and $75 \%$ respectively. The high efficiency of experiential learning indicates the workability of the methodology, its technical and qualitative superiority over standardized methodologies of the examination of psycho-speech development of young children. Criteria for analysis of levels of communicative development and classification of data may be useful for interpreting the results of diagnostic work of speech therapists working with different categories of 2-3year-olds with disabilities.

This diagnostic methodology and practical recommendations for speech therapy work with children, taking into account the levels of their communicative development, are presented under the programmers of the refresher courses and professional retraining for speech therapists and defectologists, which are implemented jointly by the Institute of Special Education and Psychology and the Institute of Lifelong Learning of MSPU [11]. 
In particular, during the preparation and professional retraining of personnel for the system of inclusive education the specific of correctional assistance for children at various stages of dysontogenesis is revealed in the process of training the Magisters in the educational program "Speech Therapy Support in Education and Healthcare" and the students of advanced training courses in additional education program "Organization and implementation of inclusive education of disabled children in educational organizations in accordance with GEF" (as part of the module "Professional activities of specialists of psycho-pedagogical support in inclusive education in accordance with GEF PE and GEF PGE of disabled students") "Modern Approaches to Speech Therapy for Children in Preschool Education".

Currently, as part of the professional retraining of teachers, the Department of Speech Therapy of Moscow State Pedagogical University has developed a program "Speech Aids to Disabled Children in Accordance with GEF." This program takes into account all the above-mentioned problematic aspects of the training of a modern speech therapist for special and inclusive education systems for children with various developmental disabilities. The program is focused not only on retraining already working teachers, but also on advanced training of students of various pedagogical specialties.

The program includes modules of practical work, namely internships for students on the basis of educational organizations in Moscow, in which children with various options of development disorder are brought up and studied.

This program is guided by trends of reforming of special education of disabled children and is based on current approaches to psycho-pedagogical support $[12,13,14,15,16]$. According to the feedback of students who have completed the training course, it is very relevant and demanded in the system of professional training and retraining of speech therapists.

The testing of the program in the 2019-2020 academic year, even when switching to distance learning because of the pandemic, showed high performance and made it possible to train thirty speech therapists with modern knowledge and skills that they are able to apply in practice.

\section{Conclusions}

Communicative development is necessary for the successful socialization of a person in society [17]. Any obstacles in its building and development, including those of a social nature, aggravate dysontogenesis, create a deformation in the development of a person's personality and contribute to manifestations of maladjustment and disorders of a sociocommunicative nature. The early period is very important for the initiation of corrective influence $[8,9,10]$. Specialists need the interest and assistance of parents in detecting and overcoming detected deviations of communicative speech development [8]. In this regard, technologies that promote coordinated interaction between specialists and parents are in demand for productive corrective and developmental work with young children to prevent and overcome communicative disorders [9]. Specialized training courses for subject-matter experts capable of solving the discussed problems routinely are also important $[11,18]$. Therefore, it is advisable to integrate this topic not only into the educational programs of master's studies and advanced training courses, which has already shown its effectiveness, but also into the general program of speech therapy for the education of students studying in undergraduate programs $[3,11,17,18,19,20]$. The development of extracurriculars for educating the undergraduate students in this field can be an interesting and useful continuation of the discussed topic and the prospect of our work, which is currently being discussed as a project. 


\section{References}

1. O.G. Prikhodko, O.V. Yugova, The formation of an early assistance system in Russia. Monograph., p. 126 (Moscow, Paradigm Publ., 2015)

2. O.G. Prikhodko, Model of improvement of psycho-pedagogical assistance for children with developmental disabilities in a single educational space of the city of Moscow. Special education, 4, 93-103 (2011)

3. T.N. Volkovskaya, On the issue of improving the professional training of a speech therapist. Secondary vocational education, 8, 42-43 (2010)

4. Yu.Ye. Vyatleva, Topical issues of the organization of speech assistance for children of preschool and school age with speech disorders: Speech assistance in the conditions of special and inclusive education: traditions and innovations: collection of academic articles. based on the materials of the international scientific and practical conference, 62-72 (Moscow, Paradigm Publ., 2019)

5. Ju.A. Shulekina, Language competence of children with speech disorders (interdisciplinary aspect). Bulletin of Education and Science. Pedagogics. Psychology. Medicine, 3, 34-38 (2012)

6. V.V. Yakusheva, Formation of personal qualities and professional competencies of a magister in the field of modernization of the research process of speech and its violations: Pedagogical journal, 6 (5A), 196-206 (2016)

7. Yu.A. Pokrovskaya, History and main approaches to the study of the essence of delayed speech development: World of special pedagogy and psychology. Scientific and practical almanac, 1, 159-165 (Moscow, LOGOMAG Publ., 2014)

8. O.V. Yugova, Communications in the triad: children with disabilities - their families support specialists: Communicative approach in the system of special and inclusive education of children with disabilities: a collection of scientific articles on the materials of the Interregional Scientific and Practical Conference, 284-290 (Moscow, Paradigm Publ., 2019)

9. N.Yu. Grigorenko, Forming the foundations of children communication of the first years of life with normal and abnormal development. Monograph, 336 p. (Moscow, Logomag Publ., 2020)

10. N.Yu. Grigorenko, Assessment of communicative development of young children with various developmental deviations by levels: World of special pedagogy and psychology. Scientific and practical almanac, 12-13, 81-90 (Moscow, Logomag Publ., 2020)

11. N.Yu. Grigorenko, Topical problems of training and vocational training of speech therapists in conditions of educational system reform: Communicative approach in the system of special and inclusive education of children with disabilities. A collection of scientific articles on the materials of the Interregional Scientific and Practical Conference, 88-94 (Moscow, Paradigm Publ., 2019)

12. Law of the Russian Federation "On Education" 273-FL. Chapter 1. General position. Article 3. Basic principles of state policy and legal regulation of relations in the field of education. (https://zakonbase.ru/zakony/ob-obrazovanii/ (accessed 27 September 2020)

13. N.N. Malofeev, O.I. Kukushkina, O.S. Nikolskaya, E.L. Goncharova, Concept of the special federal state educational standard for children with disabilities, $42 \mathrm{p}$. (Moscow, Enlightenment Publ., 2013) 
14. I.Yu. Levchenko, Problems of implementing the federal state educational standard for primary general education of students with locomotor disorders: Development of Russian defectological science and practice in the modern educational space: a new view: Second All-Russian Congress of Defectologists, 41-45 (Mosow, Publishing House MIRAKL, 2018)

15. S.Yu. Ilyina, I.A. Filatova, Development of a training system for a defectologist teacher in Russia at the turn of the 20th-21st centuries: Special education, 3 (39), 100114 (2015)

16. Yu.E. Vyatleva, V.S. Kalmykova, The problem of the relationship and continuity of the activities of speech therapists of a preschool educational institution in the conditions of modernization of the domestic education system: World of special pedagogy and psychology. Scientific and practical almanac, 1, 60-67 (Moscow, Logomag Publ., 2014)

17. N.Y. Grigorenko, I.P. Tverdokhlebova, Universal toolkit for the formation of professional socio-communicative and speech competencies for future speech therapists and foreign language teachers: Foreign languages at school, 2, 2-9 (2020)

18. Yu.A. Pokrovskaya, Modern requirements for the professional training of speech therapists: Proc. Int. Sci. Conf. "Speech therapy technologies in the conditions of inclusive education of children with speech disorders", 69-76 (Yekaterinburg, 2013)

19. V.V. Manuylova, Modeling of a practical-oriented environment in the system of training personnel in the field of "special (defectological) education": Special education, 1, 85-93 (2016)

20. I.Yu. Levchenko, Some issues of training specialists for working in psychological, medical and pedagogical commissions: Correctional pedagogy: theory and practice, 2 (7 b), 11-17 (2018) 